\title{
A Case Report of Patients with Persistence of Sciatic Artery
}

\author{
Arie Franco ${ }^{1 *}$, William B Bates ${ }^{2}$ and Jayanth H Keshavamurthy ${ }^{2}$ \\ ${ }^{1}$ University of Rochester Medical Center, 601 Elmwood Avenue, Rochester, NY 14642, USA
}

${ }^{2}$ Medical College of Georgia at Augusta University, $112015^{\text {th }}$ Street, Augusta, GA 30912, USA

\begin{abstract}
Persistence of sciatic artery is a rare vascular anomaly with an incidence of 0.03 to $0.06 \%$. It has a high incidence of complications such as aneurysm formation and ischemia, either of which may lead to an amputation in $8 \%$. We report three cases with incidental findings of persistence of sciatic arteries, which two of them were previously treated. One of our cases had additional vascular variants of a common trunk between the right brachiocephalic artery, a right hepatic artery branching from the superior mesenteric artery, and a left hepatic artery branching from the left gastric artery. This association was not previously reported and we postulate that there may be a link between these variants during the vascular embryogenesis.
\end{abstract}

Keywords: Sciatic artery; Vascular anomaly; Brachiocephalic artery; Hysterectomy; Femoral artery

\section{Case Report}

We report three patients with persistent sciatic artery. The first patient was a 60 year-old male who was admitted with lumbar pain following a motor vehicle accident. The patient had a history of autosomal dominant polycystic kidney disease. Bilateral sciatic artery was seen in imaging. The patient had aneurysm of the left sciatic artery and the right sciatic artery was previously occluded with Amplatz device (Figure 1).

The second patient was a 44-year-old African-American male with a known left lower extremity swelling admitted for trauma injury and found to have incomplete type of sciatic artery. The patient was treated with proximal and distal embolization and had a complete relief of symptoms (Figure 2).

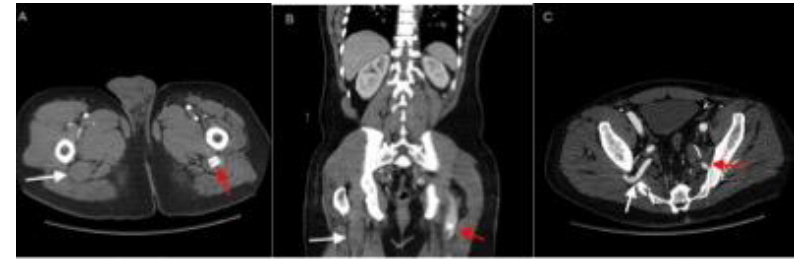

Figure 1: Computed tomography in (a) axial and (b) coronal views demonstrates 166 a thrombosed right sciatic artery (white arrow) and an Amplatz devise occluding 167 the left sciatic artery (red arrow). The axial view (c) at the level of the lower pelvis 168 demonstrates the bilateral sciatic arteries (arrows).

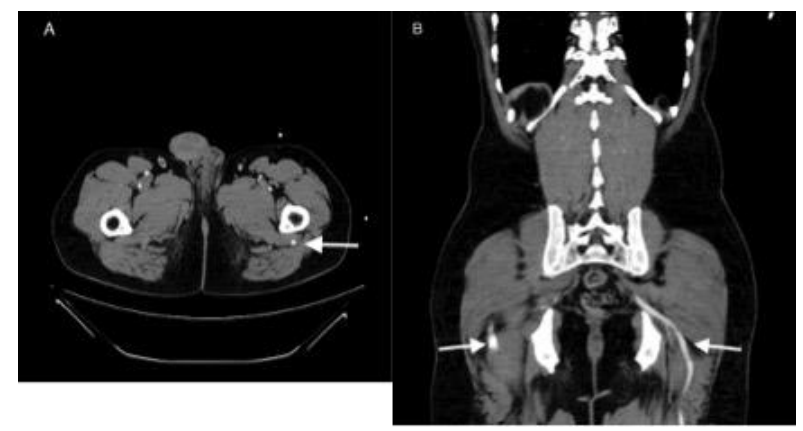

Figure 2: Axial (A) and coronal (B) computed tomography demonstrate the sciatic 173 arteries (arrows).
The third patient was a 37-year-old African-American woman with acquired immunodeficiency syndrome, presented for vaginal hysterectomy and left hemorrhagic ovarian cyst. The patient had a history of mucinous neoplasm of the body and tail of pancreas. Bilateral sciatic artery was an incidental finding in imaging (Figure 3). The images demonstrated normal variants of a common trunk between the right brachiocephalic artery, a right hepatic artery branching from the superior mesenteric artery, and a left hepatic artery branching from the left gastric artery (Figures 4 and 5).

\section{Discussion}

The primitive sciatic artery arises from the umbilical artery and is a continuation of the internal iliac artery to supply the embryological developing lower limb bud. Later, segments of this embryonic artery persist as popliteal and peroneal arteries [1]. This embryonic vascular supply is replaced by the development of the external iliac, common femoral and superficial/profunda junction [2]. If the distal superficial femoral artery does not fully develop, persistence of the primitive sciatic artery may be the result [2]. There are cases reported of coexistence of

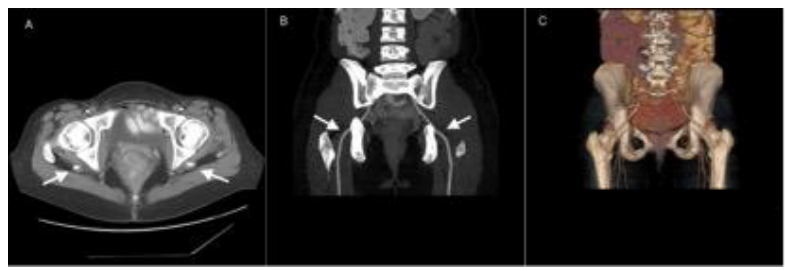

Figure 3: Axial (A), Coronal (B), and three-dimensional rendered Computed 179 tomography $(C)$ demonstrate bilateral persistent sciatic arteries.

*Corresponding author: Arie Franco, University of Rochester Medical Center 601 Elmwood Avenue, Rochester, NY 14642, USA, Tel: 585-276-3000; E-mail: arie_franco@urmc.rochester.edu

Received September 20, 2017; Accepted October 06, 2017; Published October 17, 2017

Citation: Franco A, Bates WB, Keshavamurthy JH (2017) A Case Report of Patients with Persistence of Sciatic Artery. J Vasc Med Surg 5: 343. doi: 10.4172/2329-6925.1000343

Copyright: ( 2017 Franco A, et al. This is an open-access article distributed under the terms of the Creative Commons Attribution License, which permits unrestricted use, distribution, and reproduction in any medium, provided the original author and source are credited. 


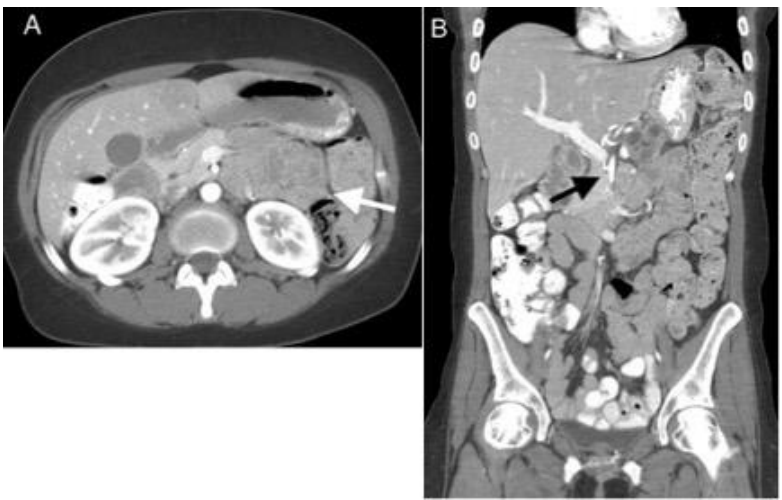

Figure 4: (A) Axial computed tomography demonstrates a mucinous neoplasm of 186 the body and tail of the pancreas (arrow). B) Coronal computed tomography 187 demonstrates a right hepatic artery branching from the superior mesenteric artery 188 (arrow).

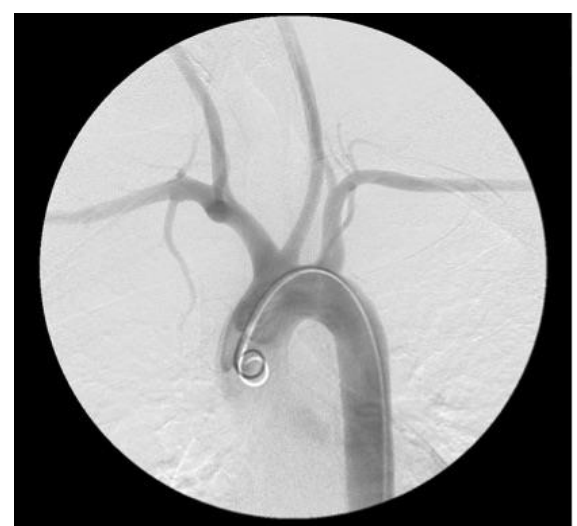

Figure 5: Angiography that was performed for other reasons demonstrates 194 common trunk between the right brachiocephalic artery and the left common 195 carotid artery.

the sciatic artery with the superficial femoral artery, although the latter may be hypoplastic [1-3].

Persistence of a sciatic artery was first reported in a post-mortem case by Green [4] in 1832. When the sciatic artery persists it is usually tortuous and enlarged vessel [5]. This is a rare vascular anomaly with an incidence of 0.03 to $0.06 \%$. It has a high incidence of complications such as aneurysm formation and ischemia, either of which may lead to an amputation in $8 \%$ [6]. The persistence of the sciatic artery is classified as the complete and incomplete types. The incomplete type is the existence of a hypoplastic persistent sciatic artery along with the dominant superficial femoral vessel. The complete type entails the existence of a dominant persistent sciatic artery along with a hypoplastic superficial femoral system, which only provides collateral supply to the lower limb [7-9].

A more detailed classification was described by Pillet et al. $[10,11]$ of four different types of persistent sciatic artery: type 1 represents complete persistence of sciatic artery with a normal femoral artery; type 2 is a complete persistence of sciatic artery in combination with incomplete development of the femoral artery type 3 is incomplete persistence of the sciatic artery in which only the upper part persists and the femoral artery is normal; and type 4 is an incomplete persistence of the sciatic artery and only the lower part persists and normal femoral artery. A fifth type was added by Gauffre et al.: a persistent sciatic artery originating by median sacral artery [12].

The clinical symptoms of persistent sciatic artery may manifest at any age with slight male predominance $[2,13]$. Fifty percent of the cases are bilateral. The presenting symptoms are pain, numbness, and motor impairment that result from compression of the sciatic nerve that lie adjacent to the persistent aberrant vessel $[2,7,9]$. The most common complication of persistence of sciatic artery is formation of aneurysm, occurring in $48 \%$ of cases [6]. It usually forms between the piriform muscle and the posterior aspect of the femoral greater trochanter, where the artery has slight S-curve $[6,14]$. The thrombus may form in the aneurysm that may cause an embolus [15]. Stenosis and occlusion may also be seen with persistence of a sciatic artery with an incidence of 7 and $9 \%$ respectively [6].

Persistent sciatic artery was reported to be associated with Mullerian agenesis [16], arteriovenous fistula [17], with hypertrophy of the lower limb, and with varicose veins $[6,18]$.

Treatment options vary and depend on the patient symptomatology. Asymptomatic patients do not need any particular treatment aside for a follow-up with Ankle-Brachial index, Doppler sonography, CT angiography, or MR angiography. Aneurysm can be occluded or ligated with precaution that the femoral artery demonstrates adequate blood supply to the lower extremity. Stenoses can be stented. In cases that there is no adequate blood flow by the femoral artery, bypass graft can be performed. When excision of the sciatic aneurysm is combined with an interposition graft, the patency may be compromised when the patient sits down $[6,15]$. Exclusion of a sciatic aneurysm may also be complicated by sciatic nerve damage [6].

Our third case had other vascular variants of a common trunk between the right brachiocephalic artery, right hepatic artery branching from the superior mesenteric artery and a left hepatic artery branching from the left gastric artery. We could not find any previous reports of such associations with the persistence of the sciatic arteries, but we can assume that there is some link that may occur during the vascular embryogenesis.

This article does not contain any studies with human participants or animals performed by any of the authors.

For this type of study formal consent is not required.

\section{References}

1. Senior HD (1920) The development of the human femoral artery, a correction Anat Res 17: 271-279.

2. Mandell VS, Jacques PF, Delany DJ, Oberheu V (1985) Persistent Sciatic Artery: Clinical, Embryologic, and Angiographic Features. AJR 144: 245-249.

3. Finerty JC (1947) Persistent ischiatic artery. Anat Rec 98: 587-595.

4. Green PH (1832) On a new variety of the femoral artery: with observations Lancet 1: 730-731.

5. Lin CW, Lee RC, Cheng HC, Soong TC, Ko JS, et al. (1999) MR angiography of persistent sciatic artery. J Vasc Interv Radiol 10: 1119-1121.

6. Van Hooft IM, Zeebregts CJ, Van Sterkenburg SMM, De Vries WR, Reijnen MMPJ (2009) The Persistent Sciatic Artery. Eur J Vasc Endovasc Surg 37: 585-591.

7. Kesri G, Mangtani J, Kumar G, KK Dangayach (2014) Persistent Sciatic Artery Aneurysm with Lower Limb Ischemia. Case Rep Vasc Med 2014: 183969.

8. Bower EB, Smullens SN, Parke WW (1977) Clinical aspects of persistent sciatic artery: report of two cases and review of the literature. Surgery 81: 588-595.

9. Batchelor TJP, Vowden P (2000) A persistent sciatic artery aneurysm with an 
Citation: Franco A, Bates WB, Keshavamurthy JH (2017) A Case Report of Patients with Persistence of Sciatic Artery. J Vasc Med Surg 5: 343. doi: 10.4172/2329-6925.1000343

Page 3 of 3

associated internal Iliac artery aneurysm. European Journal of Vascular and Endovascular Surgery 20: 400-402.

10. Pillet J, Cronier P, Mercier PH, Chevalier JM (1982) The ischiopopliteal arterial trunk: A report of two cases. Anat Clin 3: 329-331.

11. Pillet J, Albaret $P$, Toulemonde JL, Cronier $P$, Raimbeau G, et al. (1980) Tronc arteriel ischiopoplite, persistance del'artere axiale. Bull Assoc Anat 64: 109-122.

12. Gauffre S, Lasjaunias P, Zerah M (1994) Sciatic artery: A case, review of literature and attempt of systematization. Surg Radiol Anat 16: 105-109.

13. Shutze WP, Garrett WV, Smith BL (1993) Persistent sciatic artery: collective review and management. Annals of Vascular Surgery 7: 303-310.
14. Paraskevas G, Papaziogas B, Gigis J, Mylonas A, Gigis P (2004) The persistence of the sciatic artery. Folia Morphol 63: 515-518.

15. McLellan GL, Morettin LB (1982) Persistent sciatic artery: clinical, surgical, and angiographic aspects. Arch Surg 117: 817-822.

16. Agrawal AK, Gupta SK, Khanna S, Goel AK (1982) Persistent primitive sciatic artery associated with Mullerian agenesis and solitary kidney. Int Surg 67: 277278.

17. Kurtoglu Z, Uluutku $H$ (2001) Persistent sciatic vessels associated with an arteriovenous malformation. J Anat 199: 349-351.

18. Williams LR, Flangian DP, O'Connor RJ, Schuler JJ (1983) Persistent sciatic artery. Clinical aspects and operative management. Am J Surg 145: 687-693. 